
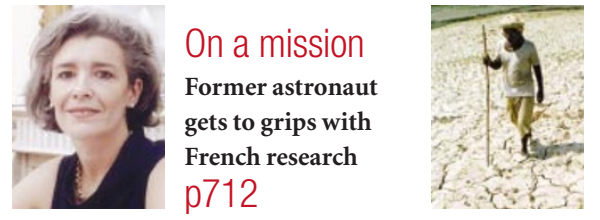

Data drought

Storm brews over

India's weather

forecasting

p713

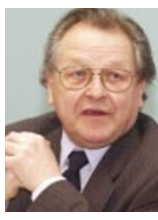

Bitter pill

Britain's medical

research faces

funding crisis

p714

Gloomy outlook

Brown haze sparks

fears of climate

change

p716

\title{
Senators attack Pentagon over weak state of defence research
}

\section{Geoff Brumfiel, Washington}

Prominent US senators have charged the Department of Defense with doing too little to halt the brain drain from laboratories that carry out research for the US military.

In a letter to Donald Rumsfeld, the defence secretary, seven members of the powerful Senate Committee on Armed Services, led by

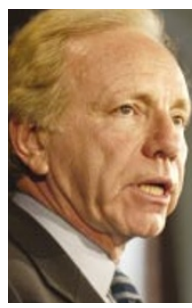

Joe Lieberman: blasts Pentagon.

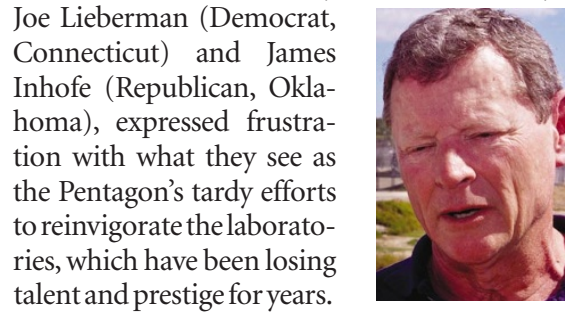

In particular, the senators attacked the Pentagon for failing to exploit special hiring systems, created by Congress, to attract young scientists back to the labs. "We have become increasingly dissatisfied with the systematic underutilization of these provisions," the 1 August letter complained.

The Pentagon's research system includes the three major service laboratories - for the Army, Air Force and Navy - as well as a number of specialized testing centres, employing
Dissatisfied:

James Inhofe.

a total of nearly 15,000 people. The Naval Research Laboratory based in Washington DC, in particular, was once a renowned centre of international excellence in several disciplines. But since the end of the cold war, the laboratory's workforce has shrunk by about a third, and many of the staff are now nearing retirement, says Vice Admiral Paul Gaffney,

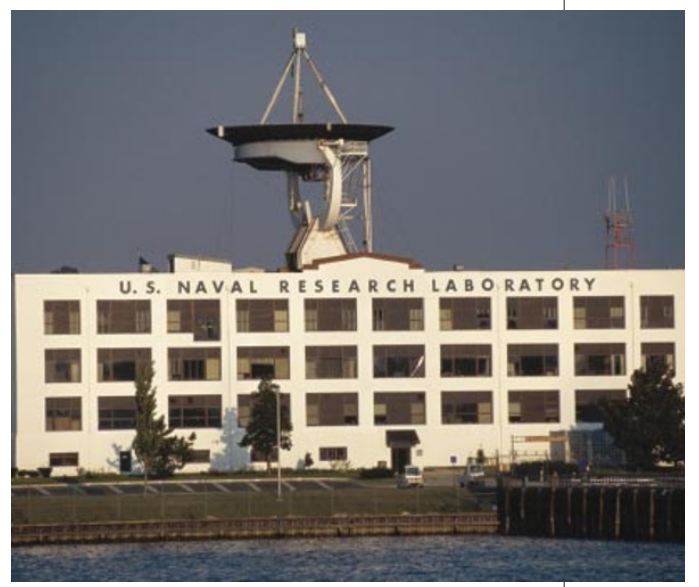

All at sea? The Navy's research laboratory has faced problems attracting young staff.

to be granted authority to hire and fire without the approval of Pentagon bureaucrats. "Congress gave the Department of Defense this ability and they haven't done anything with it," says one Senate staff member.

Cynthia Colin, a Pentagon spokeswoman, said she could not comment as officials had not had time to review the letter and formulate a response.

\section{Online cheats leave Asian students facing paper exam}

\section{Erika Check, Washington}

Tens of thousands of students from four Asian countries are to be barred from taking part in the Graduate Record Examination (GRE) general test online after their compatriots were found cheating in it.

Administered by the Educational Testing Service (ETS), the exam tests skills, such as mathematics and English-language ability, of graduate school entrants in the United States. The ETS says that students in China, Hong Kong, Taiwan and Korea will have to take paper versions of the test this autumn, after officials uncovered large-scale cheating on the verbal section of the online GRE.

The ETS says it unearthed two websites where students had posted questions and answers that they had memorized while taking the test. These questions had been used many times in the online test.

Participation in the test is required by most US graduate schools as part of candidates' admission applications.

The ETS will not say how many students accessed the websites. But its spokesman Tom Ewing says that the cheating was confined to the four countries where students will now have to take the paper test. More than 55,000 students took the computer-based GRE last year in the four countries, and Ewing says that a "substantial number of students" must have cheated, as average scores for the verbal section rose by as much as 100 points during a single testing cycle. Each section is graded on a 200-800-point scale.

But some graduate students are concerned that the paper GRE will not be directly comparable to the online version to be taken by students in the rest of the world. "The ETS should investigate and clarify the extent of cheating, so that students would not be suspected unnecessarily," says Ying Wong, a graduate student in psychology and member of the graduate student council at Stanford University in California. "It would be very damaging to the general Asian student population's morale if they feel their reputation cannot be cleared," Wong says. 